\title{
BLENDING SCIENCE AND ART: AN EDUCATIONAL PERSPECTIVE
}

\author{
Nur Balkır ${ }^{1}$, Konca Saher ${ }^{2}$, Gurkan Mihci ${ }^{3}$ \\ ${ }^{1}$ Department of Visual Communication Design, Kadir Has University (TURKEY) \\ ${ }^{2}$ Department of Interior Architecture, Kadir Has University (TURKEY) \\ ${ }^{3}$ Department of Visual Communication Design, Herron School of Art and Design \\ (UNITED STATES)
}

\begin{abstract}
Art and design education enable students to find creative and logical solutions to various design problems. The use of materials, constructive analysis, craftmanship, and originality are some key criteria in the process. Size and dimensionality, the proportion analysis, expression integrity, substantiality, and presentability can vary depending on the project and the context. As one of the methods used to provide targeted experience and learning in art and design education, interdisciplinary work presents a right ground for complex design issues. The workshop we carried out together with the Tubitak National Metrology Institution (UME) named "Art's Metrology, Metrology's Art" aimed to transform art, design, and science together into a product. As rational, natural, and appropriate connections can be established between art and science, students were asked to develop a method to meet the objectives and criteria of both around a certain conceptual focus.
\end{abstract}

An important inclusive of the workshop was to have students observe, get informed, and engage in dialogue and ultimately increase their curiosity about a certain mechanism outside of their studies. The group dynamic in the process of creating three-dimensional and displayable works within a scheduled time was supported by a scientist from the metrology department, three art and design instructors, Konca Şaher, Nur Balkır, and Gürkan Mıhçı from Kadir Has University. The finished works were then exhibited in the Tubitak-UME in Gebze compound.

This study, which blends science and art, provided students with the opportunity to experiment with a science field, and to develop their predictions about their own disciplines. The paper will present the development and the outcome of the workshop.

Keywords: science, art, interdisciplinary, metrology, workshop.

\section{INTRODUCTION}

There is a growing disconnect between engineering education and arts and design education which results in a growing disconnect between engineers and artists and designers. Typical engineering curricula place heavy emphasis on science and engineering topics. Art and design education has elements of science and engineering in its curricula; however, it is still concentrated on its own vocabulary and language of the discipline. As Ken Arnold (2017) puts it, "Ever since it made sense to think, symbolically at least, about science and art in separate worlds, they have been caught in an elaborate dance, getting closer only then to drift apart." (p.334) To Arnold, it has never been easy to disentangle them.

In today's world, it is important that a professional has a broad knowledge and grounding in other disciplines and especially in arts. This understanding of intersection of arts and one's own discipline allow one to effectively navigate different social/professional environments while understanding the language of a specific professional discipline and arts. Therefore, it becomes important to consider an integrated approach to education which blends science and arts together and creates a platform to translate concepts of science and arts into each other to describe the world around us. Describing the world around us requires to be able to break out of the old and rigid pattern of thought and seek for creative solutions, as Kalpana Paranjape (2007) pointed out. To him, "creativity in science and arts essentially originates in man's response to Nature's beauty" (p.219).

The apparent boundaries among them can be integrated through mutual contributions from each discipline (Raiffa, 2002). As a result of such discussions at Kadir Has University and the Scientific and Technological Research Council of Turkey (TUBITAK) - National Metrology Institution (UME), the present authors examined themes that can integrate arts and science and developed a workshop entitled "Art's Metrology, Metrology's Art" aimed to transform art, design, and science together into a 
product/art object at April/May 2016. This paper gives a brief explanation of this workshop, discusses the outputs and attempts to contribute to the field of education by discussing the outputs and results of the workshop.

\section{METHODOLOGY}

\section{1 "Art's Metrology, Metrology's Art"}

Art's Metrology, Metrology's Art", (Fig. 1) was a 5-day workshop, which started with the visit of metrology laboratories at TUBITAK-UME, a research and development institute, by students of Kadir Has University. The students were from industrial design and interior design department from Arts and Design Faculty and from visual communication department from Faculty of Communication. The aim of the TUBITAK-UME is to ensure the reliability of all measurements conducted in Turkey, to make provisions for the integration of these measurements into the international system and to develop existing and new measurement technologies, thereby establishing the national measurement system required for ensuring the accuracy of measurements used in commercial and industrial settings. The students visited electromagnetic, high voltage, optics, acoustics, pressure and vacuum metrology laboratories for the duration of a whole day and met the engineers working in these laboratories. The engineers described their work process, their equipment and introduced the students with the concept of metrology in different fields.

The word metrology is derived from the Greek word 'metron' and contains all the theoretical and practical elements related to measurement. In order to know the value of an unknown magnitude in every aspect of life, this magnitude is compared with a known magnitude and a value is determined. A wide range of measurements are done from medical devices to doping control, electricity / water meters, flight control devices, taximeters to base stations, from the market scales to the length of the phone credits. From ancient times to the present day, measuring is at the centre of the life of mankind.

In this workshop, engineers from TUBITAK-UME and students from Kadir Has University came together to explore the boundaries of measurement science at the intersection of art and design and to understand how measurement and calibration techniques can be integrated in describing the world around us. At the end of the workshop, it was expected that new ideas and products to describe the metrology process of a specific laboratory chosen by each student or a group of students were developed. The motto of the workshop was "How do the basic principles of metrology (science of measurement) filter through the art and design colander and meet us in everyday life?"

The main aims of the workshop were:

1 To strengthen communication between measurement science, art and design disciplines and to develop new communication models.

2 To create an important discussion environment by bringing together different disciplines.

3 To create a broader legitimacy in the intersection of design, art and science.

4 To explore the possibilities of cooperation between TUBITAK-UME and the faculties of Art and Design.

5 Integration of knowledge and skills inspired by the science into arts and design field.

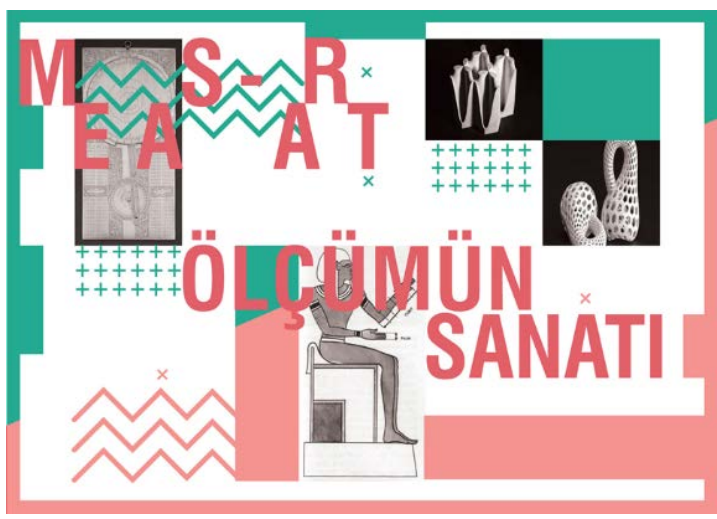

Figure 1: The pamphlet of the workshop 


\subsection{Workshop Process}

After the visit of metrology labs, there was a four-day workshop at Kadir Has University (Fig. 2 \& Fig. 3) The students started to develop their first ideas about the concept of metrology, laboratories they visited, and measurement procedures under the supervision of three university lecturers and an engineer from TUBITAK-UME. During this idea development stage, it was discussed that the end-products could be both visual representations of the laboratories as well as the students' experiences and reflections of the laboratories and measurements. Some student groups developed an idea on the machines or tools used in laboratories, while others concentrated on abstracting the units measured at the laboratories. This design stage, which was a visually thinking process was the most important part of the workshop.

The students who were trained in Visual Communication Design, Industrial Design and Interior Architecture had to encounter problems from the natural sciences, and in a very short period of time, they tried to blend the knowledge of measurement science with what their knowledge in arts and design. There were a lot of brainstorming with the university lecturers, TUBITAK-UME engineer and students to integrate these two very different disciplines into a product. As ideas began to emerge, students began to draw sketches of ideas and production drawings started to emerge. Sketching and drawing is an important part of the art and design process which enables the product to be visualized and to annotate a conceptual design. The sketches were reviewed and discussed many times by the supervisors (Fig. 4). After the sketching and drawing phase, students started to make a 3d-model of their ideas. The use of materials, constructive analysis, craftmanship, and originality were some key criteria in the process. Size and dimensionality, the proportion analysis, expression integrity, substantiality, and presentability were also among the themes discussed.

One important goal of the workshop was to expose students to an expression, an interpretation, of science which cannot be accomplished verbally, but only visually Some products used a single material and color, while some other products combined very different materials. The students attempted to reflect the impression of the metrology laboratory and measurement procedure upon them rather than developing a literal visual representation of a laboratory or a measurement equipment. This was abstraction technique adopted by arts and design students which enabled them to determine essential characteristics and primary logic of each metrology laboratory by simplifying its nature by a method of seeing, visualizing, sketching and abstracting to extract the final "core".

After the 4-day workshop period, each student or each group of students completed their interpretation of the metrology laboratory into a $3 \mathrm{~d}$ model (Fig. 5,6,7). All these models were taken to TUBITAK-UME and they were all exhibited. It created a platform for the students to discuss their ideas with the engineers of TUBITAK-UME.

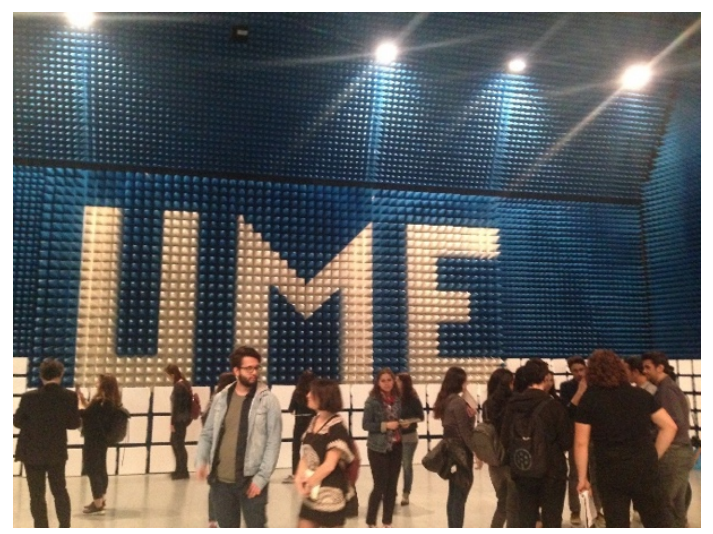

Figure 2: One of the metrology labs visited (Electro magnetic lab) 


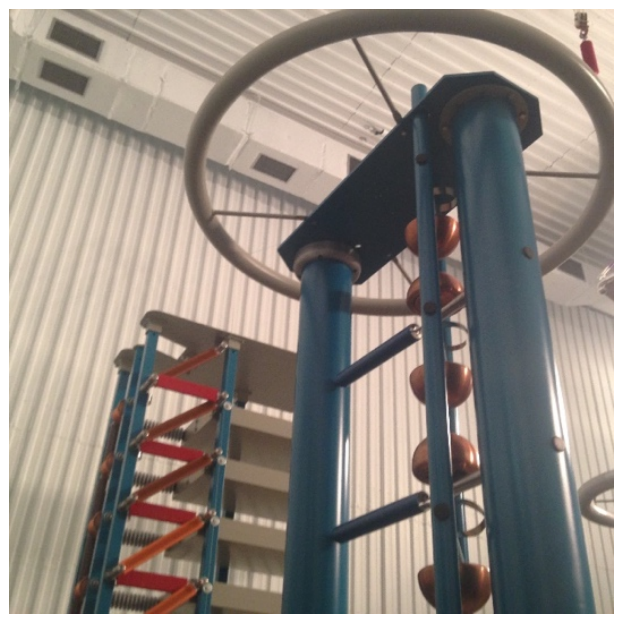

Figure 3: High voltage lab (from the UME visit)

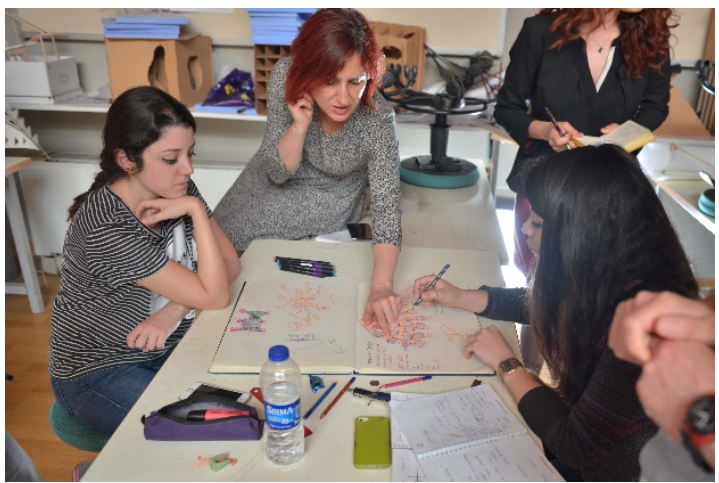

Figure: 4: Table critics

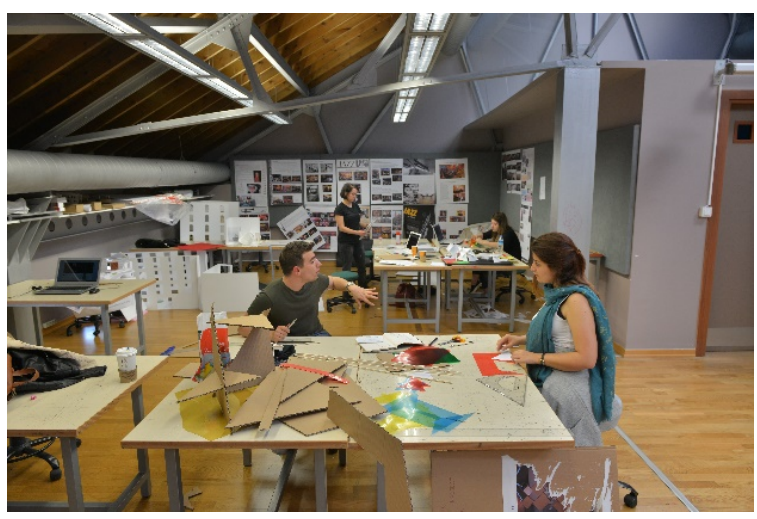

Figure 5: Work in Progress

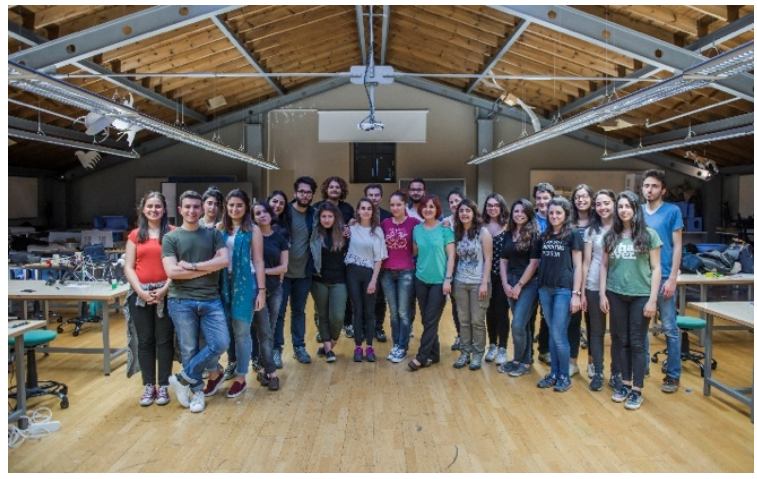

Figure 6: Studio group photo 


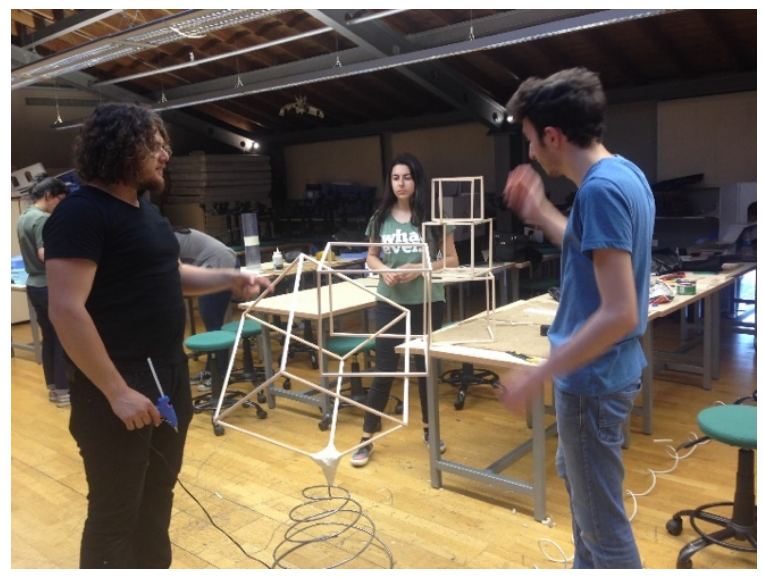

Figure 7: Model building

\section{OUTCOMES AND CONCLUSIONS}

The participant students for the workshop were chosen from three different majors, Visual Communication Design, Industrial Design and Interior Architecture. The total number of 25 students consisted of primarily $3^{\text {rd }}$ and $4^{\text {th }}$ year students. All students were excited to undertake the challenge of the workshop and prospect of exhibiting their work at TUBITAK-UME. It was also very appealing to them that they could expose their design ideas to the engineers.

The nature of the workshop provided an opportunity to establish a more personalized and relaxed teaching-learning experience between the students and workshop organizers. This new learning was an important pedagogical tool, which kept the interest and excitement of the students and workshop supervisors during the whole time of the process.

Since writing on scientific concepts would help to internalize scientific content, students were also asked to write a descriptive paper on the content and the concept of their work. These manuscripts helped students to articulate the work they were doing, so they could question the development of the complex design problem while questioning their development and seeing the connection they had with measurement systems. This study, which blends science and art, provided students with the opportunity to develop a different experience and their own subjects, while providing them with the opportunity to develop their predictions about their own disciplinary education opportunities for the workshop organizers. The workshop has been very inspiring for the cooperation between art and science, together with the experience and positive feedback, to transform into a productive cooperation for both areas and to increase partnerships to discover new forms of experiencing, seeing and interpreting the world in which it is experienced (Fig. 8,9,10). The outcomes of the workshop were then exhibited in TubitakUme, Gebze compound (Fig. 11).

The students also received feedback about value of their work by the engineers of the TUBITAK-UME. Involvement in this project fostered self-confidence and self-esteem in the participating students. One notable outcome was the important pedagogical value of the interdisciplinary learning experience.

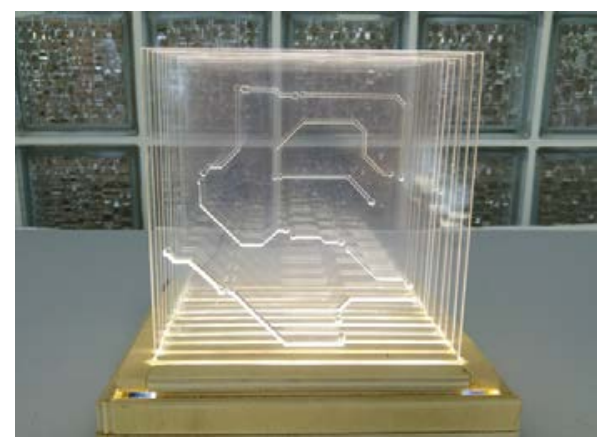

Figure 8: Student work 


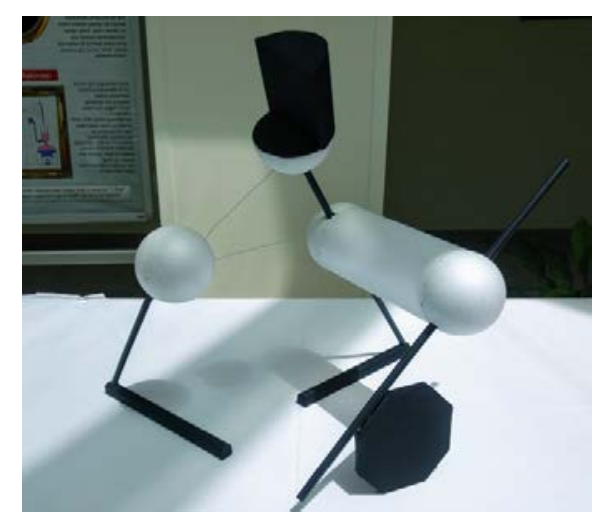

Figure 9: Student work

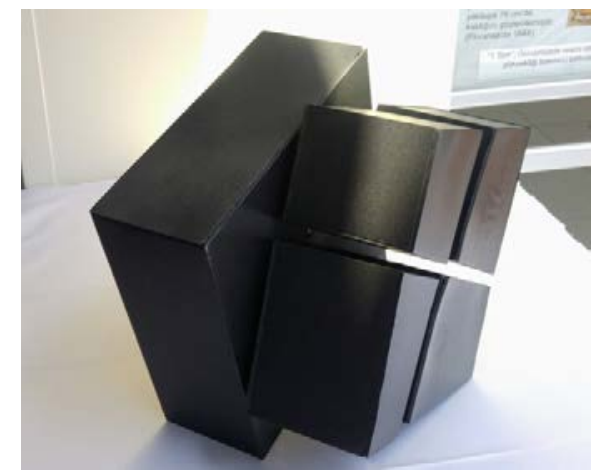

Figure 10: Student work

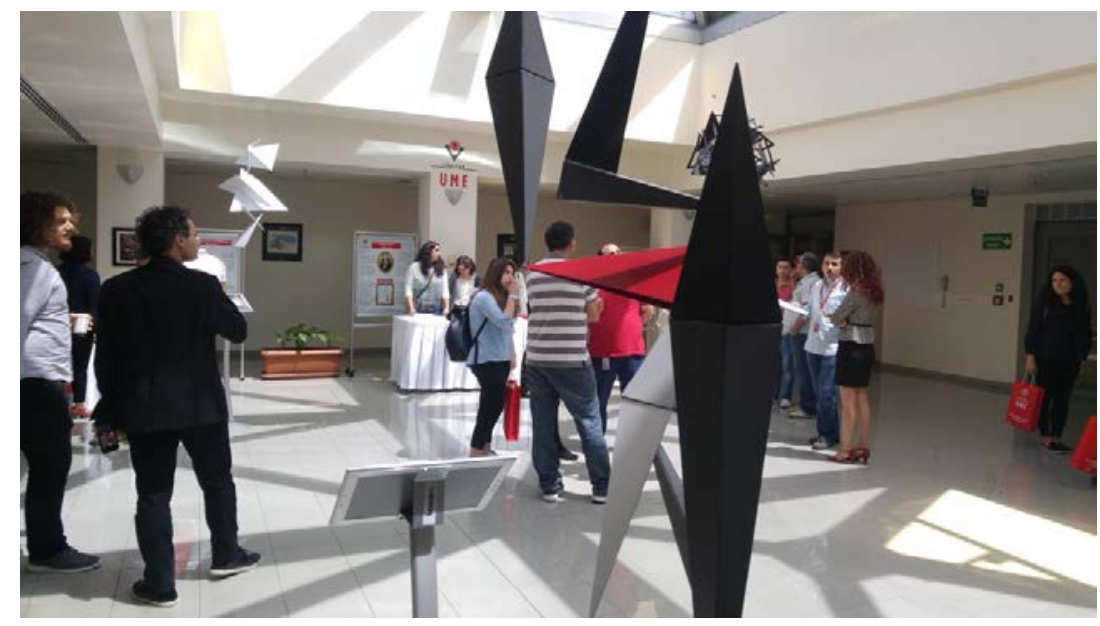

Figure 11: Exhibition Opening in Tubitak-UME, Gebze compound

\section{REFERENCES}

[1] K. Arnold, A very public affair: art meets science. Interdisciplinary Science Reviews, Routledge, Vol: 42, No: 4, pp. 331-344, 2017

[2] H. Raiffa, Negotiation analysis: The science and art of collaborative decision making. The Belknap Press of Harward University Press, Cambridge, 2002

[3] K. Saranjape, Creativity in arts and science. Annals of the Bhandarkar Oriental Research Institute, Vol. 88, pp. 219-243, 2007 